\title{
Synaptotagmin-7 as a positive regulator of glucose-induced glucagon-like peptide-1 secretion in mice
}

\author{
N. Gustavsson • Y. Wang • Y. Kang • T. Seah • S. Chua • \\ G. K. Radda • W. Han
}

Received: 3 January 2011 / Accepted: 22 February 2011 /Published online: 22 March 2011

(C) Springer-Verlag 2011

\begin{abstract}
Aims/hypothesis Glucagon-like peptide-1 (GLP-1), a hormone with potent antihyperglycaemic effects, is produced and secreted from highly specialised gut endocrine Lcells. It regulates glucose homeostasis by promoting glucose-dependent insulin secretion, suppressing glucagon secretion and enhancing insulin sensitivity. Similar to islet alpha and beta cells, L-cells are electrically excitable, and express calcium channels and ATPsensitive potassium channels. GLP-1 is also stored in secretory granules, the exocytosis of which is triggered by increased intracellular calcium levels. Although the calcium dependence of GLP-1 granule exocytosis is well established, the identities of calcium-sensing proteins in
\end{abstract}

Y. Wang and Y. Kang contributed equally to this study.

Electronic supplementary material The online version of this article (doi:10.1007/s00125-011-2119-3) contains supplementary material, which is available to authorised users.

N. Gustavsson · Y. Wang · Y. Kang · T. Seah · S. Chua •

G. K. Radda $\cdot$ W. Han $(\bowtie)$

Laboratory of Metabolic Medicine, Singapore Bioimaging

Consortium, Agency for Science,

Technology and Research (A*STAR),

02-02 Helios, 11 Biopolis Way,

Singapore 138667, Republic of Singapore

e-mail: weiping_han@sbic.a-star.edu.sg

N. Gustavsson

Department of Anatomy, Yong Loo Lin School of Medicine,

National University of Singapore,

Singapore, Republic of Singapore

Y. Wang $\cdot$ W. Han

Department of Biochemistry, Yong Loo Lin School of Medicine,

National University of Singapore,

Singapore, Republic of Singapore
GLP-1 secretion remain elusive. Here we tested whether synaptotagmin-7, a calcium sensor in pancreatic alpha and beta cells, regulates GLP-1 secretion.

Methods We studied GLP-1 secretion using synaptotagmin-7 knockout (KO) mice and GLUTag cells with lentiviralmediated synaptotagmin-7 silencing.

Results We found that synaptotagmin-7 was co-localised with GLP-1 in intestinal L-cells. GLP-1 secretion was impaired in synaptotagmin-7 KO mice when they were challenged by glucose ingestion. Lentiviral knockdown (KD) of synaptotagmin-7 in GLUTag cells led to similar reductions in GLP-1 secretion, as determined by biochemical assays and by membrane capacitance measurements. Calcium response was not altered in synaptotagmin-7 KD cells.

Conclusions/interpretation These results demonstrate that synaptotagmin-7 functions as a positive regulator of GLP-1 secretion in intestinal L-cells and GLUTag cells, consistent with its proposed role as a calcium sensor in GLP-1 secretion.

Keywords Calcium sensor - Diabetes · Exocytosis · GLP-1 . Glycaemia $\cdot$ Knockout mice

$\begin{array}{ll}\text { Abbreviations } \\ \text { GLP-1 } & \text { Glucagon-like peptide 1 } \\ \text { KD } & \text { Knockdown } \\ \text { KO } & \text { Knockout } \\ \text { KRH } & \text { Krebs-Ringer HEPES } \\ \text { shRNA } & \text { Short hairpin RNA }\end{array}$

\section{Introduction}

Glucagon-like peptide-1 (GLP-1), encoded by the proglucagon gene, is produced and secreted from gut endocrine L- 
cells in ileum and colon of the distal gut [1-3]. GLP-1 is one of the two major incretins, which have attracted great attention in recent years due to their beneficial effects on glucose and energy homeostasis [4]. GLP-1 regulates glucose homeostasis at multiple sites of action, e.g. by augmenting glucose-dependent insulin secretion, suppressing glucagon secretion and improving insulin sensitivity $[1,4]$. In addition, GLP-1 can also reduce appetite and food intake $[1,4]$. Considering the intimate link between obesity and diabetes, GLP-1 appears to be an ideal target for treatment options for both conditions. Since GLP-1 has a very short half-life, current strategies in GLP-1-based drug development include modified GLP-1 or GLP-1 analogues with longer half-life, and inhibitors of dipeptidyl peptidase-4, the enzyme that cleaves and inactivates GLP-1 [4]. An alternative option may be to target GLP-1 secretion regulation to fully utilise endogenous GLP-1 production and secretion potential of L-cells. Although progress has been made in understanding the regulation of GLP-1 secretion, many fundamental questions remain unanswered [1, 5-7].

Similar to other endocrine cells, intestinal L-cells store GLP-1 in secretory granules and release it through regulated exocytosis in response to increased intracellular calcium level [3, 8]. L-cells express calcium channels and ATP-sensitive potassium channels, and like islet alpha cells, they are electrically excitable [3,9]. Nutrient, neural and paracrine factors act through different pathways to induce GLP-1 granule exocytosis from L-cells by a common mechanism, i.e. the increase of intracellular calcium levels $[1,3,10,11]$. By analogy to insulin secretion from pancreatic beta cells, glucose, the main stimulator of GLP-1 release, was proposed to stimulate GLP-1 granule exocytosis by a series of metabolic and membrane events that include increased ATP production, closure of ATPsensitive potassium channels, opening of voltage-dependent calcium channels and elevation of cytoplasmic calcium level $[3,7]$. In addition, glucose may stimulate GLP-1 secretion by directly depolarising L-cell plasma membrane through the electrogenic action of sodium-glucose cotransporter and the consequent opening of calcium channels [6]. Although it is well established that GLP-1 release is triggered by increased calcium levels, it is not clear which proteins are responsible for sensing the calcium rise to trigger GLP-1 granule fusion with plasma membrane in L-cells.

Several members of the synaptotagmin family have been shown to function as calcium sensors in neurotransmitter and hormone release [8, 12-17]. In particular, synaptotagmin-7 regulates calcium-dependent insulin secretion in pancreatic beta cells, glucagon secretion in alpha cells and catecholamine release in chromaffin cells [15-17], and is probably the most important synaptotagmin in hormone secretion regulation. Based on the functional similarity between these cell types and L-cells, we used synaptotagmin-7 knockout (KO) mice and GLP-1-secreting murine cell line GLUTag cells with synaptotagmin-7 knockdown (KD) in this study to test whether synaptotagmin-7 is involved in the regulation of GLP-1 secretion.

\section{Methods}

Animal welfare Synaptotagmin-7 KO mice were generated as previously described [18]. All experiments involving animals were reviewed and approved by the Institutional Animal Care and Use Committee of Agency for Science, Technology and Research, Singapore (numbers 080351 and 090428).

GLP-1 secretion in vivo For oral GLP-1 secretion test, 1214-week-old mice were fasted for 16-18 h with free access to water. Plasma GLP-1 levels were tested before and 15, 30 and $60 \mathrm{~min}$ after ingestion of glucose solution given by gavage at $5 \mathrm{~g} / \mathrm{kg}$ of body weight $(50 \mu \mathrm{l}$ of blood taken per time point). The blood was mixed with $2 \mu 10.5 \mathrm{~mol} / \mathrm{l}$ EDTA and $10 \mathrm{mg} / \mathrm{ml}$ diprotin on ice and centrifuged at $10,000 \times g$ for 5 min. Plasma GLP-1 levels were determined by GLP-1 active ELISA (Millipore, St. Charles, MO, USA)

Cell culture and lentivirus-mediated silencing of synaptotagmin-7 in GLUTag cells GLUTag cells were grown in DMEM (11885; Invitrogen, New York, NY, USA) supplemented with $10 \%$ (vol./vol.) fetal bovine serum and $1 \%$ (vol./vol.) penicillin/streptomycin. The cells were plated in 12-well culture plates, and infected with synaptotagmin-7 short hairpin RNA (shRNA) lentiviral particles (sc-41320-V; Santa Cruz Biotechnology, Santa Cruz, CA, USA) and control shRNA lentiviral particles (sc-108080) according to the manufacturer's protocol. Cells were then selected by $5 \mu \mathrm{g} / \mathrm{ml}$ puromycin (Santa Cruz Biotechnology).

Immunostaining Immunolabelling was performed on frozen mouse ileal sections and GLUTag cells using rabbit antibody against synaptotagmin-7 (Synaptic Systems, Göttingen, Germany) and goat antibody against GLP-1 (Santa Cruz Biotechnology), followed by fluorescence-conjugated secondary antibodies, Alexa Fluor 488 donkey-antirabbit $\operatorname{IgG}$ and Alexa Fluor 555 donkey-anti-goat IgG (Invitrogen). Digital images of the sections were acquired on a confocal laser-scanning microscope (A1R; Nikon, Tokyo, Japan).

$R N A$ extraction and quantitative $P C R$ Total RNA was extracted from GLUTag cells using a Trizol method 
(Invitrogen), treated with DNase I (Roche, Mannheim, Germany) and reverse-transcribed with RevertAid (Fermentas, Vilnius, Lithuania). Quantitative real-time PCR was performed using Taqman assays for mouse synaptotagmin-7 $(\mathrm{Mm00444496} \mathrm{ml})$ and glucagon $(\mathrm{Mm00801714} \mathrm{ml})$ on a real-time PCR System (StepOnePlus; Applied Biosystems, Foster City, CA, USA). $\beta$-Actin from a probe set (Mouse ACTB 20× VIC-MGB; Invitrogen) was used as endogenous reference.

Measurement of GLP-1 secretion from GLUTag cells Basal medium for cell handling was Krebs-Ringer HEPES (KRH) buffer containing in mmol/l: $130 \mathrm{NaCl}, 4.7 \mathrm{KCl}$, $1.2 \mathrm{KH}_{2} \mathrm{PO}_{4}, 1.2 \mathrm{MgSO}_{4}, 2.56 \mathrm{CaCl}_{2}, 20$ HEPES supplemented with $1 \mathrm{mg} / \mathrm{ml}$ BSA and no glucose. GLUTag cells were plated in 12-well plates 1 day before the experiment to reach $60 \%$ to $80 \%$ confluence. After pre-incubation in basal KRH buffer for $2 \mathrm{~h}$, cells were washed and incubated for $30 \mathrm{~min}$ in $0.5 \mathrm{ml}$ basal KRH buffer supplemented with $10 \mathrm{mg} / \mathrm{ml}$ diprotin. The medium was collected for determination of basal GLP-1 secretion. Next KRH buffer containing $20 \mathrm{mmol} / \mathrm{l}$ glucose was added and cells were incubated for another $30 \mathrm{~min}$. Collected buffer was kept on ice and centrifuged to remove floating cells. GLP-1 concentration in the buffer was determined by GLP-1 active ELISA (Millipore). GLP-1 secretion was expressed as percentage of basal release.

Electrophysiology measurements Synaptotagmin-7 KD and control GLUTag cells were plated on coverslips 1 day before experiment. Membrane capacitance was recorded in individual cells within small clusters using the standard whole-cell patch-clamp technique [19, 20]. Exocytosis was induced by a $500 \mathrm{~ms}$ depolarising pulse from -70 to $0 \mathrm{mV}$. Pipette resistance ranged between 3 and $5 \mathrm{M} \Omega$ when pipettes were filled with intracellular solution containing (in mmol/l): $117 \mathrm{KCl}, 1 \mathrm{CaCl}_{2}, 2 \mathrm{MgCl}_{2}, 10 \mathrm{EGTA}, 5$ MgATP and 10 HEPES (pH 7.2 with $\mathrm{KOH}$ ). Extracellular solution contained (in mmol/l): $138 \mathrm{NaCl}, 5.6 \mathrm{KCl}, 2.6$ $\mathrm{CaCl}_{2}, 1.2 \mathrm{NaH}_{2} \mathrm{PO}_{4}, 4.2 \mathrm{NaHCO}_{3} 1.2 \mathrm{MgCl}_{2}, 1$ D-glucose and 10 HEPES ( $\mathrm{pH} 7.4$, with $\mathrm{NaOH})$. Cells were stimulated at low frequency $(<0.05 \mathrm{~Hz})$ to allow full recovery of exocytotic capacity between pulses. Measurements were performed using EPC10 plus patch clamp amplifier and PatchMaster software (HEKA Instruments, Bellmore, NY, USA). Exocytosis was detected as changes in cell membrane capacitance, which was estimated by the Lindau-Neher technique implementing the 'Sine + DC' feature of the lock-in module [21]. The amplitude of the sine wave was $10 \mathrm{mV}$ and the frequency was set at $1 \mathrm{kHz}$. All cell membrane capacitance measurements were performed at $30-32^{\circ} \mathrm{C}$.
Calcium measurements GLUTag cells plated on coverslips as described above were loaded with $1 \mu \mathrm{mol} / \mathrm{l}$ Fura-2 in basal KRH buffer for $40 \mathrm{~min}$ at $37^{\circ} \mathrm{C}$. Coverslips were mounted at the bottom of an open chamber under continuous perifusion of $\mathrm{KRH}$ buffer at $37^{\circ} \mathrm{C}$ [22]. Cells were stimulated with $\mathrm{KRH}$ buffer containing $20 \mathrm{mmol} / 1$ glucose for $30 \mathrm{~min}$ and the $\mathrm{Ca}^{2+}$ response was recorded from individual GLUTag cells within small clusters on an inverted microscope (Eclipse TE2000-U; Nikon) using an image analysis system (Metafluor; Molecular Devices, Sunnyvale, CA, USA). Fura-2 was excited at 340 and $380 \mathrm{~nm}$ with Lambda DG4 system (Sutter Instrument, Novato, CA, USA). After passing a bandpass filter (535DF35; Omega Optical, Brattleboro, VT, USA), the emitted signal was projected onto a CCD camera (CoolSNAP HQ2; Photometrics, Tuscon, AZ, USA) and the digital images collected. $\left[\mathrm{Ca}^{2+}\right]_{\mathrm{i}}$ was calculated from the ratio of 340 and $380 \mathrm{~nm}$ signals after background subtraction using the equation described by Grynkiewicz et al. [23], with a $K_{\mathrm{d}}$ of $224 \mathrm{nmol} / \mathrm{l}$.

Western blot Synaptotagmin-7 KD and control GLUTag cells were lysed and protein was quantified using a protein assay (DC; Bio-Rad, Hercules, CA, USA). Samples were loaded and resolved on a $12 \%(\mathrm{wt} / \mathrm{vol}$.) SDS-polyacrylamide gel and then transferred to a nitrocellulose membrane. The membranes were incubated overnight at $4{ }^{\circ} \mathrm{C}$ with rabbit polyclonal synaptotagmin-7 antibody (Synaptic Systems) or mouse monoclonal $\beta$-actin antibody (Santa Cruz Biotechnology). After incubation with horseradishconjugated anti-rabbit IgG (GE Healthcare, Piscataway, NJ, USA), the ECL chemiluminescent system (GE Healthcare) was used for signal detection.

Statistical analysis The data are presented as means \pm SEM. Comparisons of data were made using the two-tailed Student's $t$ test with significance limit set at $p<0.05$.

\section{Results}

Detection of synaptotagmin-7 in intestinal L-cells We first examined by immunohistochemistry whether synaptotagmin7 was produced in GLP-1-secreting L-cells. L-cells were identified by GLP-1 immunolabelling in intestinal sections. Synaptotagmin-7 was detected in L-cells and showed similar subcellular distribution to that of GLP-1 (Fig. 1). As expected, no immunoreactivity to synaptotagmin-7 was observed in synaptotagmin-7 KO intestinal sections, where GLP-1 staining had a similar pattern to that in the control mice (Fig. 1). 
Fig. 1 Detection of synaptotagmin-7 in intestinal L-cells. Intestinal sections $(10 \mu \mathrm{m})$ were stained with antibodies against synaptotagmin-7 and GLP-1, followed by fluorescence-conjugated secondary antibodies. Representative images, taken on a confocal microscope, are shown. Synaptotagmin-7 (green) was produced in GLP-1-positive cells and shown to have a high degree of overlap with GLP-1 signals (red). Arrows indicate selected overlapping signals of synaptotagmin-7 and GLP-1. For comparison, no immunoreactivity to synaptotagmin-7 was detected in intestinal sections from synaptotagmin-7 KO $\left(\mathrm{Syt}^{-1}\right)$ mice. $n=4$ mice of each genotype. Scale bars: $5 \mu \mathrm{m}$ (Control) and $20 \mu \mathrm{m}\left(\mathrm{Syt}^{--}\right)$
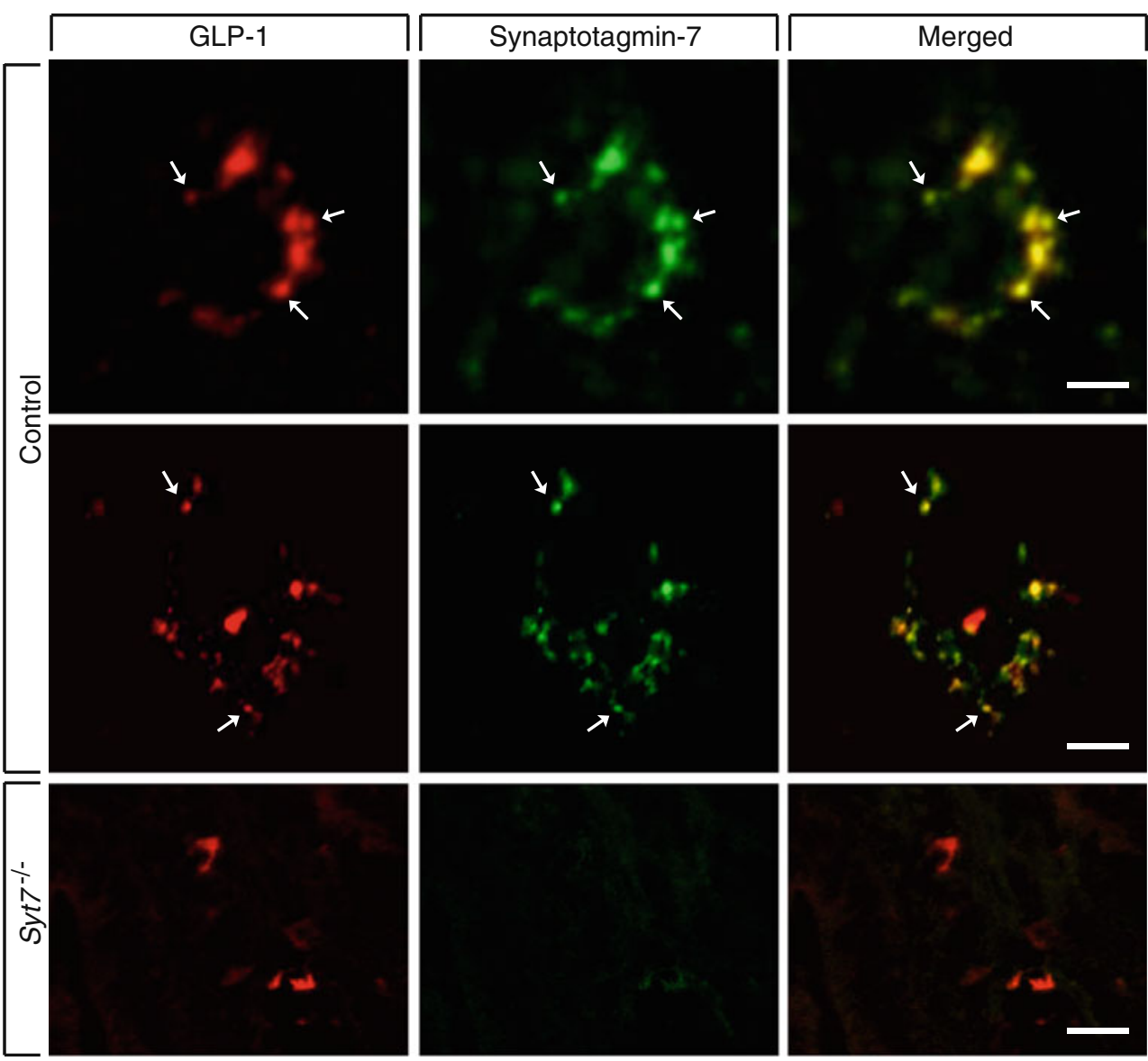

Impaired GLP-1 secretion in synaptotagmin-7 KO mice As synaptotagmin-7 functions as a calcium sensor regulating insulin and glucagon granule exocytosis, and possibly as a key regulator of other hormone and neuropeptide secretion, we tested whether deletion of synaptotagmin-7 affected GLP-1 levels and/or GLP-1 secretory response. Fasting plasma levels of GLP-1 were lower in synaptotagmin-7 KO mice than in the wild-type control $(1.98 \pm 0.40$ vs $4.14 \pm$ $0.53 \mathrm{pmol} / \mathrm{l}, p<0.005)$, an initial indication that GLP-1 secretion is defective in synaptotagmin-7 $\mathrm{KO}$ mice. We then measured glucose-induced GLP-1 secretion in synaptotagmin$7 \mathrm{KO}$ and control mice. Glucose ingestion induced an approximately two- to threefold increase in GLP-1 secretion from basal resting level. GLP-1 secretion increased gradually and peaked at $30 \mathrm{~min}$ after stimulation in synaptotagmin-7 $\mathrm{KO}$ and control mice. However, synaptotagmin-7 KO mice exhibited markedly reduced GLP-1 levels compared with control mice (Fig. 2a). Total GLP-1 release in response to glucose ingestion, calculated as AUC after baseline subtraction, was decreased by $\sim 50 \%$ in synaptotagmin- $7 \mathrm{KO}$ mice when compared with the control mice (Fig. 2b).

Synaptotagmin-7 production in GLP-1-secreting GLUTag cells As L-cells are scattered in intestinal mucosa, it is difficult to obtain a large number of L-cells in sufficient purity for in vitro secretion analysis. Therefore we decided to test the effects of synaptotagmin-7 deletion in a wellestablished murine GLP-1-secreting cell line, GLUTag cells
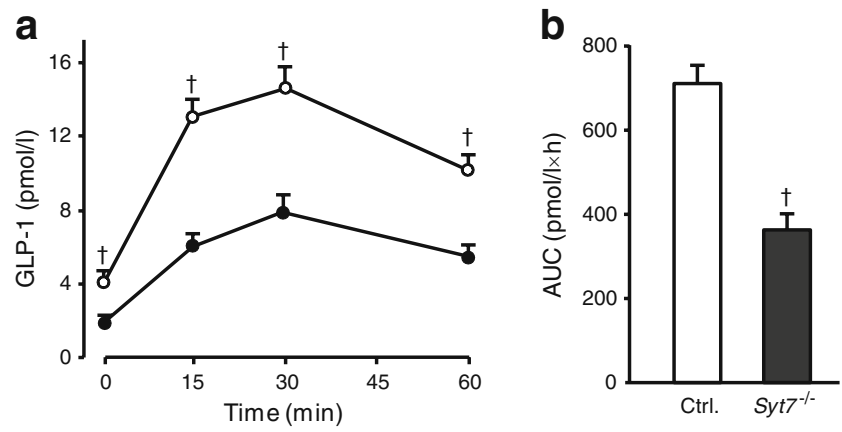

Fig. 2 Impaired GLP-1 secretion in synaptotagmin-7 KO mice. a Plasma GLP-1 levels before and 15, 30 and $60 \mathrm{~min}$ after glucose ingestion were determined in overnight-fasted synaptotagmin-7 KO (black circles) and control (white circles) mice. Both groups showed a similar pattern of GLP-1 secretion, but synaptotagmin-7 KO mice had much reduced GLP-1 levels at all time points. b Total GLP-1 secretion in synaptotagmin-7 KO $\left(\mathrm{Syt}^{-1}\right)$ (black bar) and control (Ctrl.; white bar) mice was calculated as AUC from the data in part a after baseline subtraction. $n=12$ for synaptotagmin- $7 \mathrm{KO}, n=15$ for control mice; ${ }^{\dagger} p<0.005$ 
[24]. As in intestinal L-cells, synaptotagmin-7 was detected in GLUTag cells and showed a high degree of colocalisation with GLP-1 (Fig. 3).

Impaired GLP-1 secretion in synaptotagmin-7 KD GLUTag cells Due to alternative splicing at the linker region, synaptotagmin-7 is expressed in multiple variants [25]. We performed western blot analysis and detected multiple splicing forms between $\sim 40$ and $\sim 75 \mathrm{kDa}$ in GLUTag cells (Fig. 4a). To test the function of synaptotagmin-7 in GLUTag cells, we knocked down synaptotagmin-7 expression by lentivirus-mediated RNA interference (Fig. 4a). Expression of all the variants was affected by RNA interference, with synaptotagmin-7 expression reduced by more than $70 \%$ in KD cells, when compared with GLUTag cells infected with control lentivirus carrying a scrambled sequence. Other proteins, such as soluble NSF-attachment protein receptors, were not affected in synaptotagmin-7 KD cells (electronic supplementary material [ESM] Fig. 1).

Glucose-stimulated GLP-1 secretion was reduced by $\sim 60 \%$ in synaptotagmin-7 KD cells when compared with control GLUTag cells (Fig. 4b). Using the whole-cell patch clamp technique, we also measured depolarisation-evoked GLP-1 granule exocytosis and found impaired GLP-1 granule exocytosis in synaptotagmin-7 $\mathrm{KD}$ cells, as indicated by the smaller capacitance jump after the depolarisation pulse (Fig. 4c). As summarised in Fig. 4d, the mean amplitude of the capacitance jump in synaptotagmin-7 KD GLUTag cells was approximately half of that in control cells. Together, these results show that GLP-1 granule exocytosis was severely impaired in synaptotagmin-7 KD GLUTag cells.

Normal GLP-1 content and calcium responses in synaptotagmin-7 KD GLUTag cells To determine whether the reduction in GLP-1 secretion and impaired GLP-1 granule exocytosis was due to defects at steps upstream of calcium sensing and membrane fusion, we first tested the expression of proglucagon gene in synaptotagmin-7 KD and control GLUTag cells. We found no difference between the two groups (relative expression levels $1.0 \pm 0.1$ and $0.8 \pm$ 0.1 for control and synaptotagmin-7 KD cells, respectively; $n=3$ independent experiments, each performed in triplicate). We also measured total GLP-1 content, finding it to be the same in control and synaptotagmin-7 KD GLUTag cells $(3.0 \pm 0.2$ vs $2.7 \pm 0.2 \mu \mathrm{g} / \mathrm{mg}$ for control and synaptotagmin-7 KD cells, respectively; $n=3$ independent experiments, each performed in triplicate). We next recorded cytoplasmic calcium changes in response to $20 \mathrm{mmol} / \mathrm{l}$ glucose stimulation. High glucose induced a rapid increase in calcium levels in synaptotagmin-7 KD and control cells. There was no difference in glucose-induced calcium response pattern (ESM Fig. 2a), lag time $(52 \pm 3$ and $50 \pm 3 \mathrm{~s}, n=15$ and 21 for control and synaptotagmin-7 KD cells, respectively [ESM Fig. 2b]) or peak amplitude of the response $(267 \pm 17$ and $245 \pm 22 \mathrm{nmol} / \mathrm{l}, n=15$ and 21 for control and synaptotagmin-7 KD cells, respectively [ESM Fig. 2c]). Together, these results indicate that the impairment of GLP-1 secretion and GLP-1 granule exocytosis was due to defects downstream of the calcium signal.

\section{Discussion}

Synaptotagmin-7 functions as a calcium sensor regulating two of the key islet hormones, namely insulin and glucagon, as well as catecholamine from adrenal chromaffin cells $[8,15-17]$. Like synaptotagmin-1, -2 and -9 , which function as principal calcium sensors for neurotransmitter release in respective brain regions, synaptotagmin-7 appears to be a key calcium-sensing protein in endocrine and neuropeptide secretion [12-14]. In this study, we found that synaptotagmin-7 regulates GLP-1 secretion and may serve as a calcium sensor in intestinal L-cells. Synaptotagmin-7 was detected in GLP-1-positive cells in mouse intestinal epithelium. Moreover, mice with deletion of synaptotagmin-7
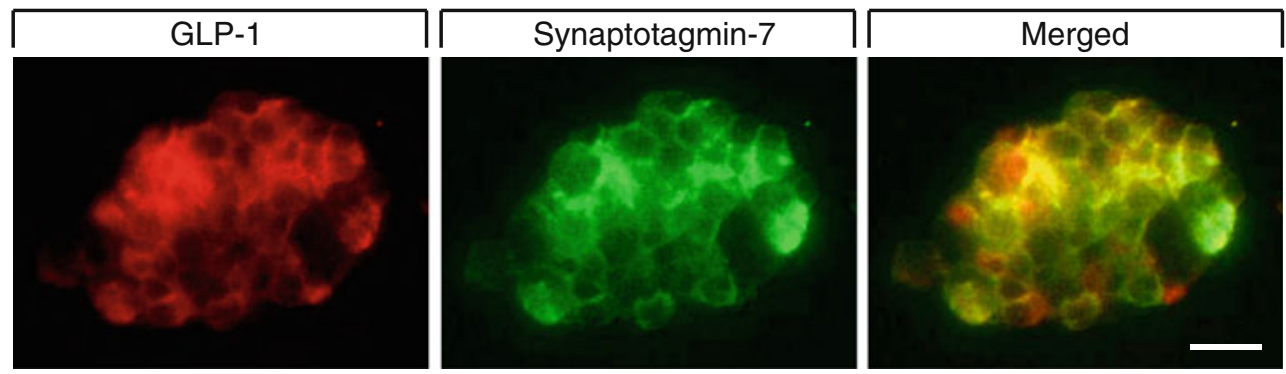

Fig. 3 Synaptotagmin-7 expression in GLUTag cells. GLUTag cells were stained with antibodies against synaptotagmin-7 and GLP-1, followed by fluorescence-conjugated secondary antibodies. Images were taken on a confocal microscope. Synaptotagmin-7 (green) was present in GLUTag cells, with a high degree of overlap with GLP-1 signals (red). $n=8$ coverslips from three separate cell preparations. Scale bar: $20 \mu \mathrm{m}$ 

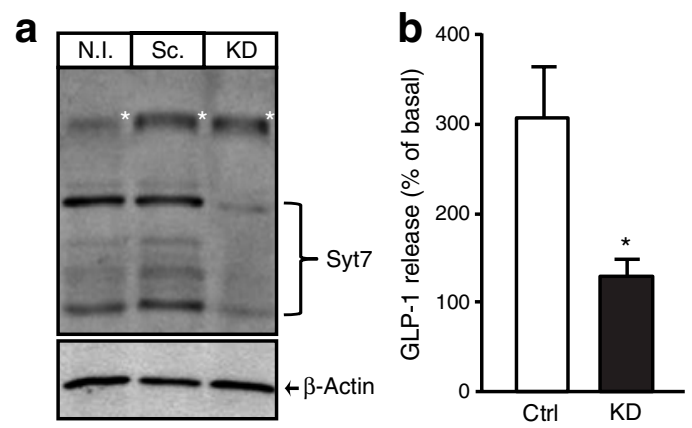

Fig. 4 Reduced GLP-1 granule exocytosis in GLUTag cells with lentiviral-mediated synaptotagmin-7 knockdown. a Immunoblot showing efficient silencing of synaptotagmin-7 expression by lentiviral-mediated RNA interference. Synaptotagmin-7 was produced in multiple isoforms in GLUTag cells. Production of all the isoforms could be efficiently knocked down. $\beta$-Actin was used as loading control. Asterisks indicate a non-specific band recognised by the synaptotagmin-7 antibody. N.I., non-infected; Sc., control infected with lentivirus carrying a scrambled sequence. b Reduced GLP-1 secretion in GLUTag cells with synaptotagmin-7 KD. Control (Ctrl) and synaptotagmin-7 KD GLUTag cells were incubated at 0 (basal) and then at $20 \mathrm{mmol} / \mathrm{l}$ glucose (stimulated) for $30 \mathrm{~min}$. Stimulated
C

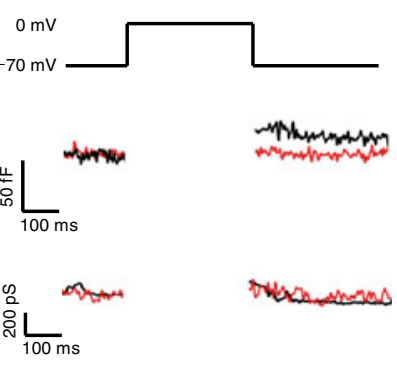

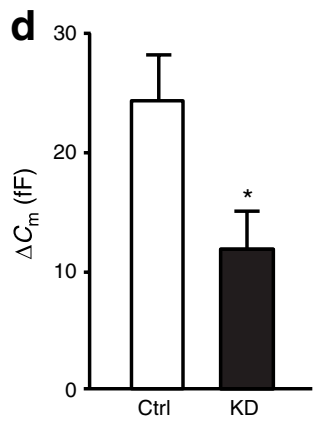

secretion is expressed as percentage over basal secretion. Data are presented as means \pm SEM of three independent experiments, each performed in triplicate. ${ }^{*} p<0.05$. c Membrane capacitance was recorded in control and synaptotagmin-7 KD GLUTag cells. Capacitance increase (fF) elicited by $500 \mathrm{~ms}$ depolarisations from -70 to $0 \mathrm{mV}$ in synaptotagmin-7 $\mathrm{KD}$ cells (red trace) was lower than in control cells (black trace). Membrane conductance (pS) during the recording is also shown. d Recordings from similar experiments to those above (c), summarised and presented as means \pm SEM. $n=5$ and $n=7$ for control and synaptotagmin-7 KD cells; $* p<0.05 . C_{\mathrm{m}}$, membrane capacitance

process of establishing cell cultures that mimic the polarity of L-cells in intestinal epithelium $[3,7]$.

Since the discovery of GLP-1 in the 1980s, increasing efforts have been directed at understanding GLP-1 action and pharmacokinetics, as well as at developing therapeutic use of GLP-1-based strategies. Examples of these efforts are long half-life GLP-1 analogues and agents that inhibit GLP-1 degrading enzymes to extend the availability of endogenous GLP-1 [1, 2, 4]. Given the many benefits and success of GLP-1-based therapies in treating diabetes, it is highly relevant to understand the secretion control of GLP1 , including the biogenesis and exocytosis mechanisms of GLP-1-containing granules. While data on the mechanisms of GLP-1 secretion are sketchy, it appears that the stimulussecretion cascade of glucose-induced GLP-1 secretion may be similar to that of pancreatic beta cells, although GLP-1 release displays a more sustained pattern compared with the biphasic pattern of insulin [3]. Considering that synaptotagmin-7 controls the final steps of GLP-1 granule exocytosis, enhancement of synaptotagmin-7 activity in triggering GLP-1 release could be a way towards fully utilising the endogenous production and secretion potential of GLP-1.

In addition to its actions on glucose sensors and food intake, GLP-1 participates in control of glycaemia by potently stimulating insulin secretion and inhibiting glucagon secretion. We have previously shown impaired insulin secretion and nearly abolished glucagon secretion in synaptotagmin- $7 \mathrm{KO}$ mice $[15,16]$. It is possible that reduced GLP-1 secretion could contribute to the insulin exocytosis defects. However, technical hurdles remain in the 
secretion defect in synaptotagmin-7 $\mathrm{KO}$ mice, but the extent of the GLP-1 effect is likely to be limited, as these KO mice maintain postprandial normoglycaemia [15]. GLP-1 may inhibit glucagon secretion by acting directly on alpha cells via GLP-1 receptors on alpha cells or indirectly by stimulating insulin and somatostatin secretion [1]. In either pathway, reduced GLP-1 levels would lead to increased glucagon secretion. Thus reduced GLP-1 secretion is unlikely to have contributed to the observed glucagon secretion phenotype in synaptotagmin-7 KO mice.

In conclusion, our finding that synaptotagmin-7 serves as a positive regulator in GLP-1 secretion represents an important step in understanding the control of GLP-1 release. The present study, along with previous studies on the role of synaptotagmin-7 in islet alpha and beta cells, and in adrenal chromaffin cells, suggests that synaptotagmin-7 acts as a key calcium sensor in endocrine and neuroendocrine secretion [15-17].

Acknowledgements This study was supported by intramural funding from Agency for Science, Technology and Research, Singapore and the Biomedical Research Council (to W. Han). We thank D. Drucker (Department of Medicine, University of Toronto) for the GLUTag cells, C. Wollheim (Department of Cell Physiology and Metabolism, University of Geneva) for helpful discussions and C. Khaw of SBIC-Nikon Imaging Centre for assistance with fluorescence microscopy.

Duality of interest The authors declare that there is no duality of interest associated with this manuscript.

\section{References}

1. Drucker DJ (2006) The biology of incretin hormones. Cell Metab 3:153-165

2. Drucker DJ, Philippe J, Mojsov S, Chick WL, Habener JF (1987) Glucagon-like peptide I stimulates insulin gene expression and increases cyclic AMP levels in a rat islet cell line. Proc Natl Acad Sci USA 84:3434-3438

3. Tolhurst G, Reimann F, Gribble FM (2009) Nutritional regulation of glucagon-like peptide-1 secretion. J Physiol 587:27-32

4. Lovshin JA, Drucker DJ (2009) Incretin-based therapies for type 2 diabetes mellitus. Nat Rev Endocrinol 5:262-269

5. Gribble FM (2008) RD Lawrence Lecture 2008: targeting GLP-1 release as a potential strategy for the therapy of type 2 diabetes. Diabet Med 25:889-894

6. Gribble FM, Williams L, Simpson AK, Reimann F (2003) A novel glucose-sensing mechanism contributing to glucagon-like peptide-1 secretion from the GLUTag cell line. Diabetes 52:1147-1154

7. Reimann F, Habib AM, Tolhurst G, Parker HE, Rogers GJ, Gribble FM (2008) Glucose sensing in L cells: a primary cell study. Cell Metab 8:532-539
8. Gustavsson N, Han W (2009) Calcium-sensing beyond neurotransmitters: functions of synaptotagmins in neuroendocrine and endocrine secretion. Biosci Rep 29:245-259

9. Reimann F, Gribble FM (2002) Glucose-sensing in glucagon-like peptide-1-secreting cells. Diabetes 51:2757-2763

10. Gameiro A, Reimann F, Habib AM et al (2005) The neurotransmitters glycine and GABA stimulate glucagon-like peptide-1 release from the GLUTag cell line. J Physiol 569:761-772

11. Simpson AK, Ward PS, Wong KY et al (2007) Cyclic AMP triggers glucagon-like peptide-1 secretion from the GLUTag enteroendocrine cell line. Diabetologia 50:2181-2189

12. Geppert M, Goda Y, Hammer RE et al (1994) Synaptotagmin I: a major $\mathrm{Ca} 2+$ sensor for transmitter release at a central synapse. Cell 79:717-727

13. Pang ZP, Melicoff E, Padgett D et al (2006) Synaptotagmin-2 is essential for survival and contributes to $\mathrm{Ca} 2+$ triggering of neurotransmitter release in central and neuromuscular synapses. J Neurosci 26:13493-13504

14. Xu J, Mashimo T, Sudhof TC (2007) Synaptotagmin-1, -2, and -9: $\mathrm{Ca}(2+)$ sensors for fast release that specify distinct presynaptic properties in subsets of neurons. Neuron 54:567-581

15. Gustavsson N, Lao Y, Maximov A et al (2008) Impaired insulin secretion and glucose intolerance in synaptotagmin-7 null mutant mice. Proc Natl Acad Sci USA 105:3992-3997

16. Gustavsson N, Wei SH, Hoang DN et al (2009) Synaptotagmin-7 is a principal $\mathrm{Ca} 2+$ sensor for $\mathrm{Ca} 2+$-induced glucagon exocytosis in pancreas. J Physiol 587:1169-1178

17. Schonn JS, Maximov A, Lao Y, Sudhof TC, Sorensen JB (2008) Synaptotagmin-1 and -7 are functionally overlapping $\mathrm{Ca} 2+$ sensors for exocytosis in adrenal chromaffin cells. Proc Natl Acad Sci USA 105:3998-4003

18. Maximov A, Lao Y, Li H et al (2008) Genetic analysis of synaptotagmin-7 function in synaptic vesicle exocytosis. Proc Natl Acad Sci USA 105:3986-3991

19. Reimann F, Maziarz M, Flock G, Habib AM, Drucker DJ, Gribble FM (2005) Characterization and functional role of voltage gated cation conductances in the glucagon-like peptide-1 secreting GLUTag cell line. J Physiol 563:161-175

20. Hamill OP, Marty A, Neher E, Sakmann B, Sigworth FJ (1981) Improved patch-clamp techniques for high-resolution current recording from cells and cell-free membrane patches. Pflugers Arch 391:85-100

21. Lindau M, Neher E (1988) Patch-clamp techniques for timeresolved capacitance measurements in single cells. Pflugers Arch 411:137-146

22. Larsson-Nyren G, Sehlin J (1996) Comparison of the effects of perchlorate and Bay K 8644 on the dynamics of cytoplasmic Ca2+ concentration and insulin secretion in mouse beta-cells. Biochem $\mathrm{J}$ 314:167-173

23. Grynkiewicz G, Poenie M, Tsien RY (1985) A new generation of $\mathrm{Ca} 2+$ indicators with greatly improved fluorescence properties. J Biol Chem 260:3440-3450

24. Drucker DJ, Jin T, Asa SL, Young TA, Brubaker PL (1994) Activation of proglucagon gene transcription by protein kinase-A in a novel mouse enteroendocrine cell line. Mol Endocrinol 8:1646-1655

25. Sugita S, Han W, Butz S et al (2001) Synaptotagmin VII as a plasma membrane $\mathrm{Ca}(2+)$ sensor in exocytosis. Neuron 30:459-473 